\title{
Effects of X-irradiation on the kinetics of abnormal sperm production and sperm loss in the mouse
}

\author{
G. C. Pogany \\ Department of Biological Sciences, Northern Arizona University, Flagstaff, Arizona 86011, U.S.A.
}

\begin{abstract}
Summary. Exposure of male mice to $6 \mathrm{~Gy}$ of $\mathrm{X}$-rays resulted in a very rapid and extensive sloughing of the germinal epithelium as shown by the accumulation of nonsperm cells within the lumen of the epididymis. These cells were identified as stage I and 2 round spermatids. After accumulating in the caput, they progressed through the epididymis over the weeks of sampling and, by Week 9 after irradiation, they had completely disappeared from the organ. It is suggested that the precocious loss of round spermatids is responsible for the induction of oligospermy within the testis and the caput epididymidis. Similar sperm losses from the cauda epididymidis were not observed.

Radiation also enhanced the frequency of misshapen spermatozoa normally found in this strain. From kinetic considerations, it is suggested that the generation of abnormal spermatozoa may be biphasic with an early component comprising maturing spermatids and a late contingent composed of affected spermatocytes. Return to the pre-irradiation level of abnormal frequency was not observed within the time frame of this study (10 weeks), perhaps indicating residual damage.

The synchrony that existed among the various organs in terms of both sperm loss and the generation of abnormal spermatozoa may be the result of a rapid dispersion of gametes from the testis and not due to local responses as would be expected if sperm flow were affected by the irradiation.

The distribution of abnormal sperm types was different in the testis from that in the epididymis, presumably because of a testicular spermatophagic mechanism specific for the removal of certain deformities. It is concluded that the kinetics of spermatogenesis, of spermiogenesis, and of sperm transport in the mouse is not affected by exposure to $6 \mathrm{~Gy}$ of X-rays.
\end{abstract}

\section{Introduction}

A great deal of interest has been generated by the phenomenon of radiation-induced sperm malformation in rodents (Bruce et al., 1974). Hypotheses about its cause range from induced mutations (Wyrobek \& Bruce, 1975) to chromosomal aberrations (Wyrobek et al., 1975) and even DNA loss (Pinkel et al., 1983). In view of the fact that human males undergoing radiation therapy are also prone to develop the same symptoms (Hahn et al., 1976; Wyrobek et al., 1980), the investigation of the dynamics behind these malformations is of considerable practical importance. Previous reports have indicated that the peak elevation in abnormally shaped spermatozoa occurs at 5 weeks after the initial exposure and coincides with the concurrent development of an oligospermic condition (Bruce et al., 1974). Because of this unique timing, it has been suggested that early spermatocytes are the cells which sustain the damage (Bruce et al., 1974; Meistrich et al., 1978). However, the data upon which these hypotheses are based have been limited to determining the kinetics of malformation from caudal samplings alone. The rationale for this is that caudal spermatozoa are most mature and this therefore obviates the need to invoke possible maturational insufficiencies as likely 
intervening factors in the observed effects. For this to be valid, however, the assumption must be made that the kinetics of spermatogenic cell damage, as acertained through caudal samples only, is reflective of all damages sustained by the testis. This point of view is not justified since there has been no systematic inquiry into this matter.

Further justification for a detailed study of the kinetics underlying the X-ray generation of malformed spermatozoa is based on the observation that, with time, both the oligospermic condition and the elevated abnormal sperm frequency abate and a trend toward the normal preirradiation levels is observed (Bruce et al., 1974). It is not known whether recovery is complete or whether continued sperm production by the individual has been affected by residual damage. However, since this trend is anticipated, there is concern about the possible genetic consequences of fertilization involving spermatozoa whose genetic integrity may have been permanently compromised by radiation.

A more thorough understanding of the events occurring after irradiation, particularly as it applies to both the testis and the epididymis, is obviously needed. A knowledge of the synchronization between these organs is fundamental to the elucidation of the reaction of these tissues to X-ray damage as well as to the mechanism of recovery. In this investigation, I provide a detailed analysis of the responses of the testis, the caput and the cauda epididymidis of the mouse to the effects of a single dose of X-rays.

\section{Materials and Methods}

The procurement, maintenance, and the irradiation of the SW mice used in this study have been previously described (Pogany et al., 1981; Pogany \& Lewis, 1985). Briefly, all animals, including controls, were anaesthetized with pentobarbitone sodium $(80 \mathrm{mg} / \mathrm{kg}$ body wt) and placed under the beam of a Picker $\mathrm{C} 4 \mathrm{M} / 60$ therapeutic unit $80 \mathrm{~cm}$ from the source and within a field of $12 \times 12 \mathrm{~cm}$. Only the pelvic area was irradiated. Beginning on the day of irradiation and every week thereafter 2 control and 3 exposed animals were lightly anaesthetized and killed by cervical dislocation. The desired organs were separately dissected in cold Tris-saline ( $0.01 \mathrm{M}$-Tris in $0.9 \%(\mathrm{w} / \mathrm{v}) \mathrm{NaCl}, \mathrm{pH} 8.0)$ except for the testes which were first freed from the tunica before maceration. Randomly selected epididymides were used for histological processing and examination. The sperm suspensions were filtered through muslin to remove cellular debris. Sperm numbers were determined for each preparation using a haemocytometer loaded on both sides. To $0.9 \mathrm{ml}$ of each sperm suspension, $0.1 \mathrm{ml}$ of a $1 \%$ Eosin Y stock was added, mixed, and allowed to stand for $60 \mathrm{~min}$ (Wyrobek \& Bruce, 1975). Five slides per suspension were made by smearing. They were subsequently air-dried and made permanent with Permount. For each of 3 slides, 300 cells were scored to determine the incidence of sperm abnormality and the results expressed as the percentage of the total. In all representative tissues, free heads and tails were omitted from the counts. In the case of the caput where sperm numbers were very low by Week 5 after irradiation, only 100 spermatozoa per slide were counted but all 5 slides were scored. The same slides were analysed later for types of abnormalities. Six different classes of abnormalities were distinguished as (1) perforatorium: deformities or absence of a perforatorium; (2) hammer: improper insertion of the midpiece into the fossa; (3) collapsed: head shape similar to an inverted triangle; (4) truncated: a tapering of the post-acrosomal region; (5) doubles: multiples of tails or heads; (6) others: unclassifiables.

A minimum of 300 intact spermatozoa was scored for each of 3 slides per organ. In all of the above procedures, every effort was made to select randomly the slides to be analysed and to avoid the duplicate analysis of overlapping fields.

Complete epididymides were fixed in Bouin's fluid, dehydrated through the usual alcohol series, and embedded in paraffin wax. Sections were cut at $10 \mu \mathrm{m}$ and stained with haematoxylin and eosin. Individual illustrations were recorded on Plux X film through a Zeiss microscope. The negatives were developed in Microdol X and printed on RC Kodak paper.

The tracing of sperm movement through the reproductive system of the mouse involved the labelling of the gametes with $\left[{ }^{3} \mathrm{H}\right]$ thymidine (ICN Biochemicals, Irvine, $\mathrm{CA}$; sp. act. $70 \mathrm{Ci} / \mathrm{mmol}$ ). A group of 83 animals from the same source were injected intraperitoneally with $1 \mu \mathrm{Ci} / \mathrm{g}$ body weight. A subgroup of 42 mice were irradiated 22 days after the injection and under the conditions described above. Beginning on the day of irradiation, testes, caput and cauda were obtained and pooled daily from 2 unirradiated control and 3 exposed mice. Epididymal spermatozoa were obtained as described above. Sonication-resistant spermatozoa were acquired from testicular samples as described by Balhorn et al. (1984). Demembranated testes were homogenised in $10 \mathrm{ml}$ grinding medium $(0 \cdot 25 \mathrm{M}$-sucrose, $0.01 \mathrm{~m}$-Tris, $\mathrm{pH} 8.0,2.5 \mathrm{~mm}$-magnesium chloride) for $1 \mathrm{~min}$ at the highest speed of an Omnimixer. All suspensions were then washed 3 times in Tris saline. The final pellet was resuspended in $3 \mathrm{ml} 1 \%$ CTAB (cetyltrimethylammonium bromide; Sigma, St Louis, MO; No. m-7635) containing $10 \mathrm{~mm}$-DTT (dithiothreitol; Sigma, No. d-0632) and allowed to stand for $30 \mathrm{~min}$ at room temperature. The suspensions, which consisted of naked sperm nuclei (Balhorn $e t$ 
al., 1977), were washed 3 times in Tris saline to remove the excess CTAB-DTT. The final pellet was resuspended in $2 \mathrm{ml}$ Tris-saline and a sample of $0.2 \mathrm{ml}$ was transferred to $0.8 \mathrm{ml} 5 \mathrm{M}$-guanidine hydrochloride and read in a Beckman DB-GT spectrophotometer at $260 \mathrm{~nm}$. From the remaining suspension, $1.5 \mathrm{ml}$ were filtered onto Millipore filters (type $\mathrm{SC}, 8 \cdot 0 \mu \mathrm{m}$ ) and dried. The filters were then transferred to $10 \mathrm{ml}$ Instagel scintillation fluid and counted in a Tracor Analytic, Model Delta 300 spectrometer with windows set at a maximum of 260 and a minimum of 0 . The final values were expressed as counts per mg DNA determined from the spectrophotometer readings (extinction coefficient $=20$ ).

The data were statistically analysed using Student's $t$ test (two-tailed). The comparisons were made between the means of the control and exposed animals and included the standard error (s.e.). A probability of $P=0.05$ was selected as the level of significance.

\section{Results}

\section{Histological examinations}

Epididymides of exposed mice showed evidence of infiltration of the caput by what appeared to be spermatogenic cells. Low-power photomicrographs indicated that the invasion was very extensive and rapid since most epididymal tubules were already filled $24 \mathrm{~h}$ after the administration of 6 Gy to the reproductive system (Fig. 1). Subsequently, the cellular infiltration progressed to more distal sections of the epididymis. By 3 weeks after exposure the spermatogenic cell mass appeared in the corpus and, in 2 more weeks, it could be seen within the cauda (Fig. 2). While the sporadic sampling of these epididymides did not allow for the precise evaluation of the movement of these cells, the $4-5$-week transit time from the caput to the cauda indicated that their movement through the organ was much slower than that of spermatozoa. The ultimate fate of these cells could not be determined under the present experimental conditions. However, their complete clearance from the lumen of the epididymal tubules was evident by Week 9 (Fig. 2).

A more detailed examination revealed that the invading cells represented a heterogeneous population. A major component was tentatively identified as round spermatids because of the granular character of their nuclei in contrast to the more fibrillar nuclear condition of other spermatogenic cells such as spermatocytes. The presence of juxtanuclear acrosomal granules has also contributed to characterizing them as step 1 and 2 spermatids (Fig. 3, arrows). The considerable heterogeneity in nuclear size further supported their identity as spermatids since a similar condition after irradiation has been reported by Oakberg (1975). Pycnosis was also evident (Fig. 3, ' $p$ ') and attested to the severity of the radiation damage. A few dividing cells could also be recognized (Fig. 3, ' $x$ ') but their differentiation into mitotic or meiotic elements could not be made with certainty. A few multinucleated cells could also be observed. They have not yet been precisely identified.

\section{Spermatid losses}

The rapid accumulation of a large complement of spermatogenic cells within the epididymal environment suggested that sloughing of the germinal epithelium was one of the most immediate responses of the reproductive system to radiation damage. To support this contention, testicular smears were prepared and analysed from a third group of mice irradiated under identical conditions. Beginning $24 \mathrm{~h}$ after exposure and at subsequent weekly intervals, two control and two experimental testes were macerated in cold $1 \%$ sodium citrate, hypotonically treated in $0.015 \mathrm{M}-\mathrm{KCl}$, fixed in Carnoy's, and spread onto cold slides. After staining with Giemsa, the slides were scored for the number of Sertoli cells and spermatid nuclei. Since the population of Sertoli cells is not affected by an exposure of $6 \mathrm{~Gy}$ of radiation (Oakberg, 1975), the results were expressed as the ratio of spermatids to Sertoli cells. The identification of the two types of nuclei was based on previous descriptions (Bloom \& Fawcett, 1962; Clermont, 1963).

The reduction in the number of round spermatids was significantly depressed (Fig. 4 ) by $24 \mathrm{~h}$ after irradiation when compared to the control ratio of spermatids to Sertoli cells $(P<0.025)$. 

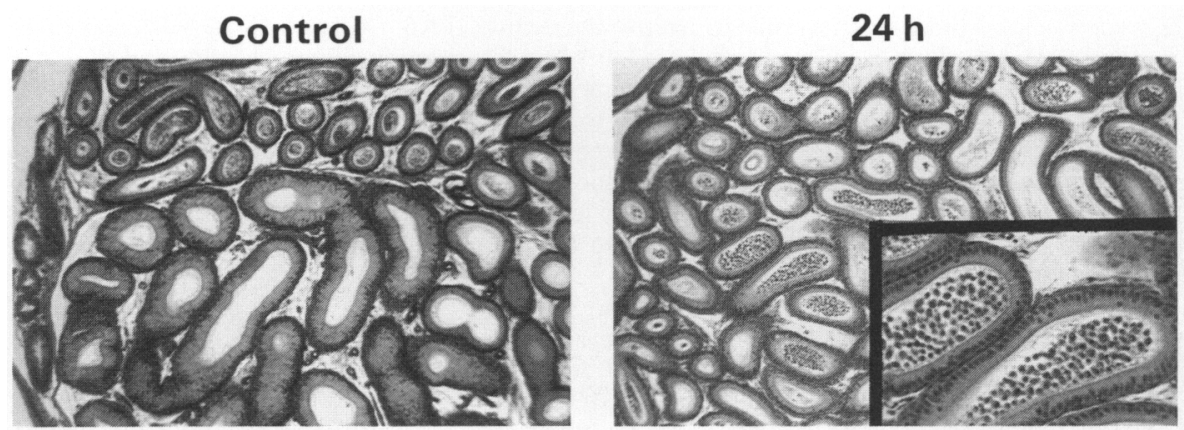

\section{Caput}
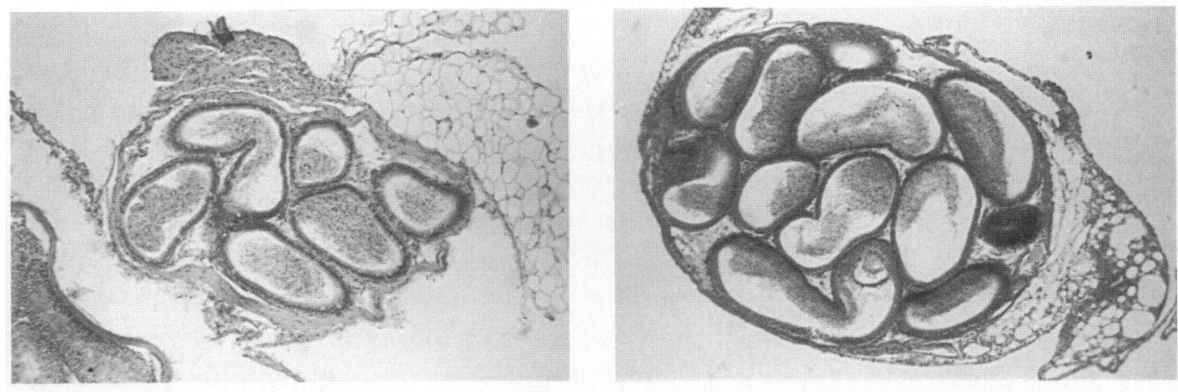

Corpus
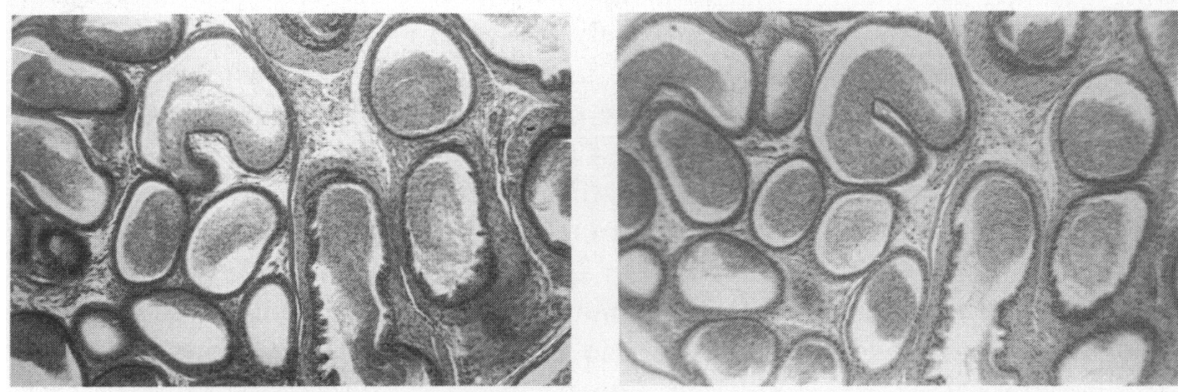

\section{Cauda}

Fig. 1. Histology of epididymides. The X-irradiation of the mouse reproductive system is accompanied by a very rapid and extensive infiltration of cells into the caput $24 \mathrm{~h}$ after exposure. $\times 520$; insert $\times 1560$.

Subsequently, the ratio of spermatids to Sertoli cells continued to fall until the number of Sertoli cells exceeded that of spermatids (Week 4). Regeneration of spermatids in the germinal epithelium was gradual but already detectable by Week 5 .

\section{Sperm losses}

A close relationship could be established between spermatid losses and the ultimate decline in sperm numbers. Weekly sperm counts made from the three regions of the reproductive system revealed obvious sperm losses from the testis and the caput 3 weeks after irradiation (Fig. 5). By Week 4 , the drop in sperm number was so severe that only about $2 \%$ of the gamete population 


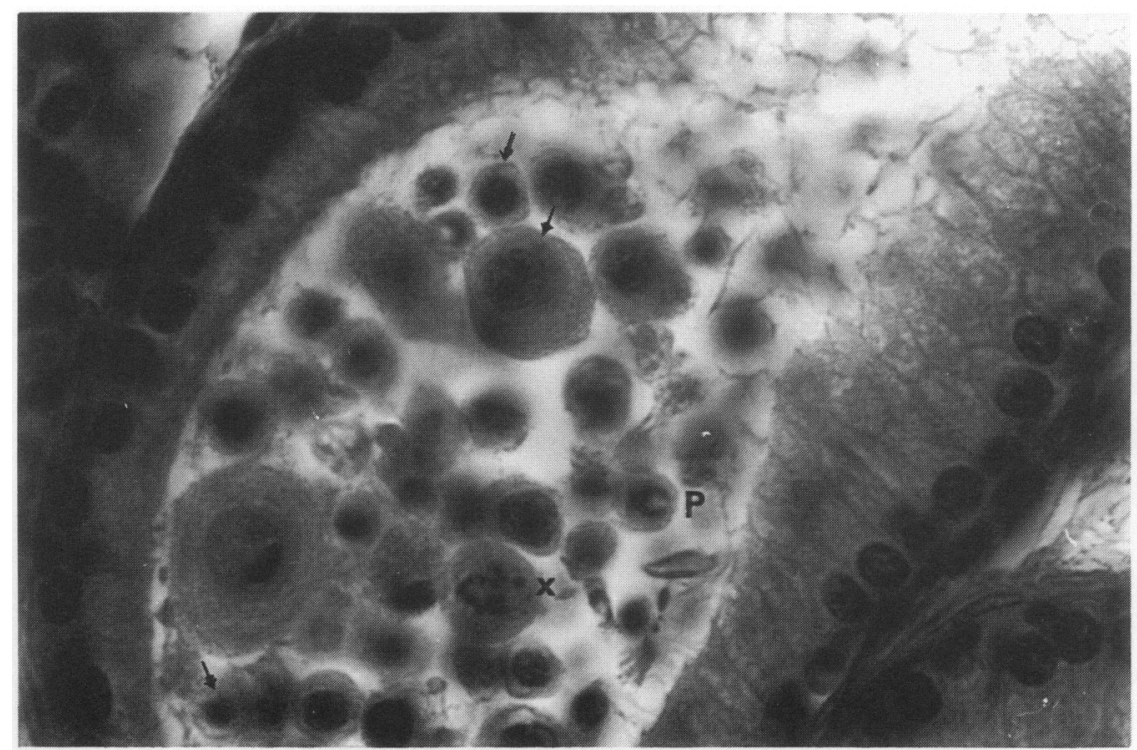

Fig. 3. Partial identification of cells found within the lumen of the caput epididymidis. Round spermatids are identifiable by their juxtanuclear acrosomal granule (arrows). Rare spermatocytes can also be seen with their conspicuous chromosomal constitution (x). The severity of the radiation damage is also apparent by the evident pycnosis in some of the nuclei $(P) . \times 5625$.

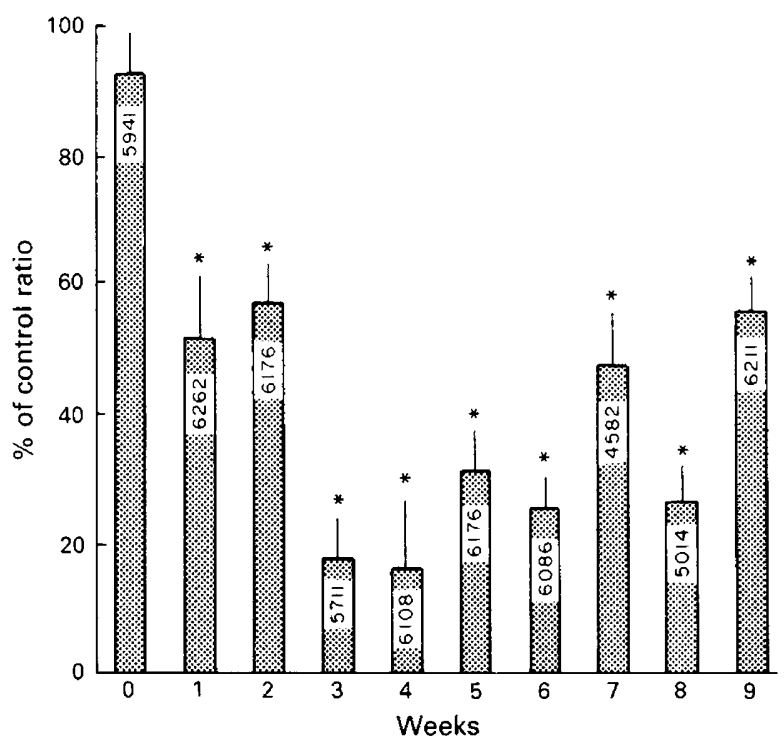

Fig. 4. The ratio of round spermatids to Sertoli cells plotted as a function of time after exposure to $6 \mathrm{~Gy}$. Values are means and s.e. for the sample sizes indicated. ${ }^{*} P<0.05$ compared with value for Week 0 . 
(a)

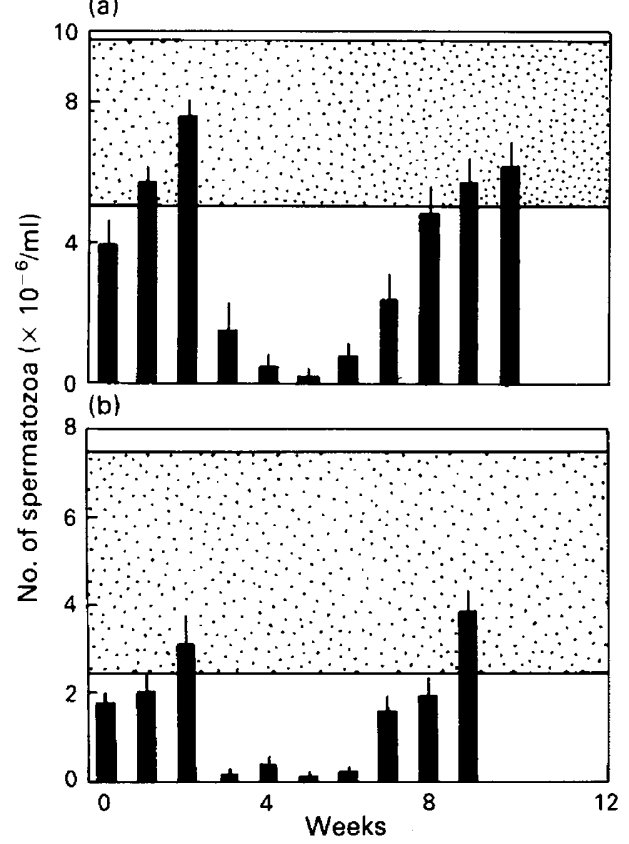

(c)

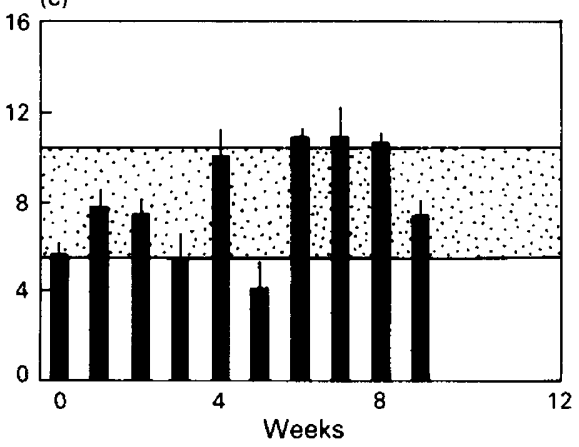

Fig. 5. The effects of $6 \mathrm{~Gy}$ on the number of spermatozoa in the testis (a) and caput (b) and cauda (c) epididymidis of the mouse. Values are means and s.e. $(n=105502)$. Control values are shown by the stippled band.
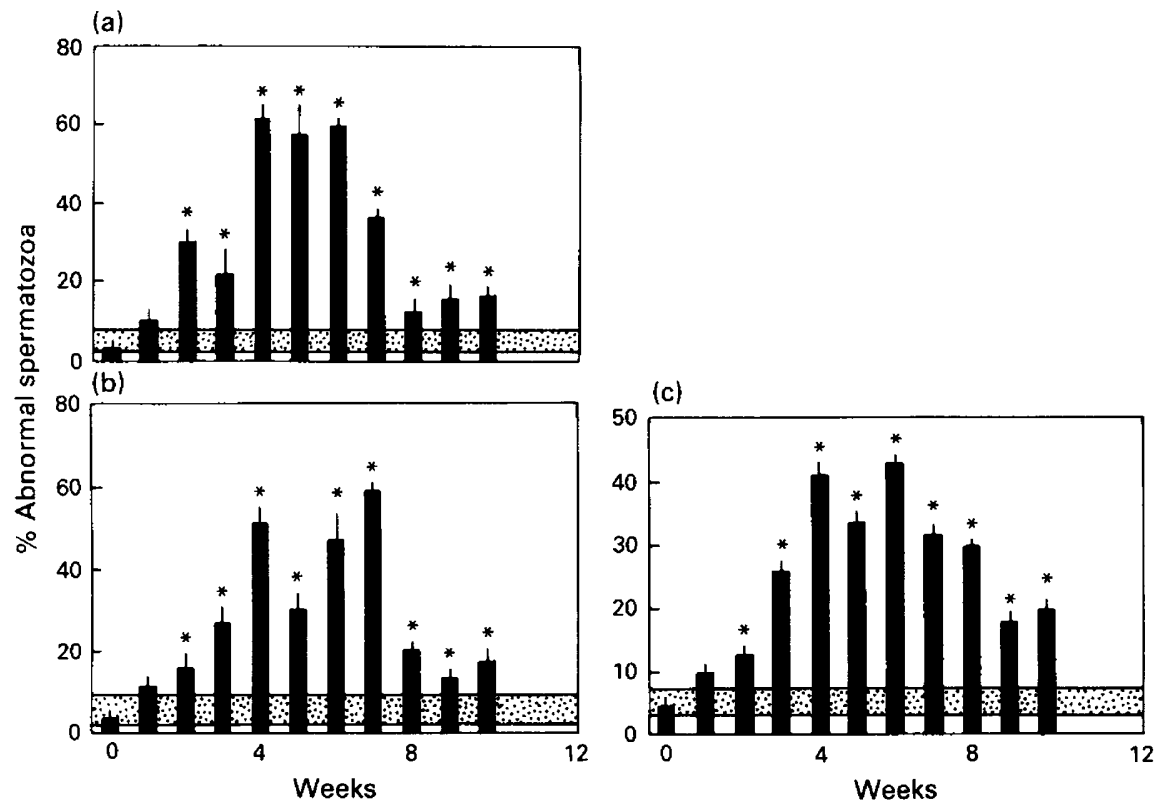

Fig. 6. The effects of X-rays on the incidence of abnormal spermatozoa in the testis (a) and caput (b) and cauda (c) epididymidis. Values are means and s.e. for 13 500, 8100, 8793, 6848, $12600,11561,9900,10800,9900$ and 13500 spermatozoa at Weeks $0,1,2,3,4,5,7,8,9$ and 10 respectively. Control values are shown by the stippled band. ${ }^{*} P<0.05$, compared with control values. 
remained countable. This condition of virtual azoospermia in the testis and the caput epididymidis was sustained for 2 more weeks after which a gradual but measurable restoration of sperm numbers could be observed.

Sperm losses in the cauda epididymidis could not be demonstrated (Fig. 5). Because of the evident high fluctuations in sperm numbers, azoospermia could only develop in the cauda if the drop in the number of spermatozoa exceeded $50 \%$. Under the present experimental conditions, this could not be established since sperm numbers remained well within the normal range of control counts.

\section{Kinetics of abnormal sperm production}

A similar synchrony of events accompanied the accumulation of additional abnormal spermatozoa (Fig. 6). The generation of abnormally shaped cells was rapid since the frequency of
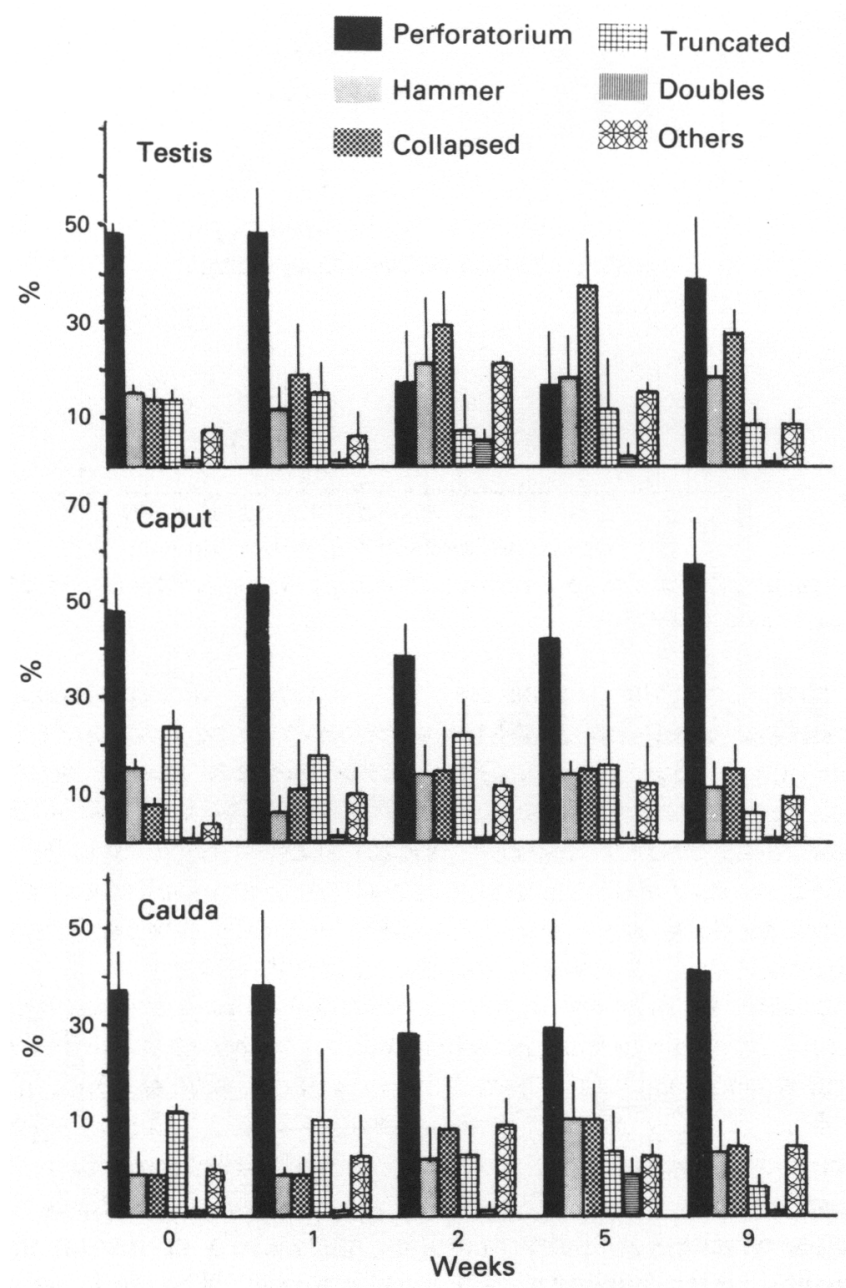

Fig. 7. The distribution of abnormal sperm types in irradiated animals. Values are means and s.e. for 33154 (testis), 30661 (caput), 31500 (cauda) spermatozoa. 


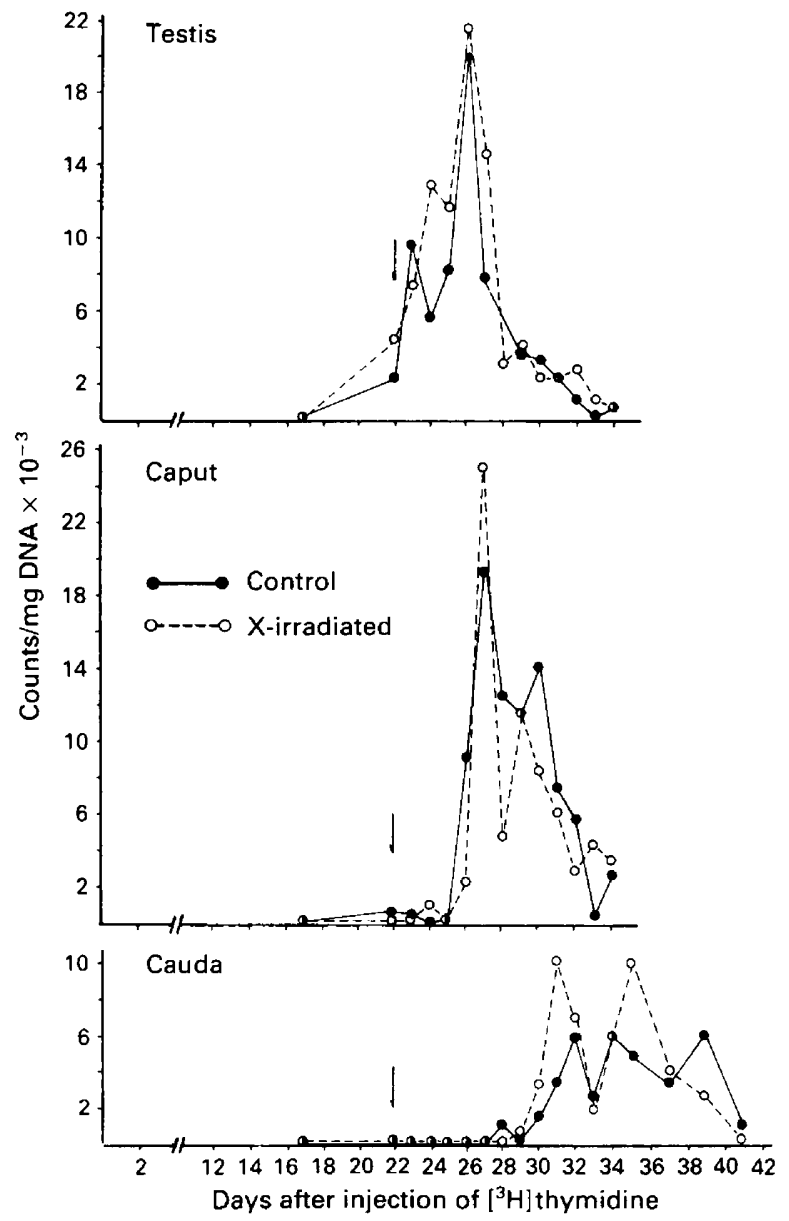

Fig. 8. The movement of labelled spermatozoa through the reproductive tract of control and irradiated mice at $6 \mathrm{~Gy}$ (arrows).

misshapen gametes rose above the normal range by Week 2 . This indicated that the radiationinduced morphological perturbations could include non-dividing elements such as maturing late spermatids. Evidence that dividing spermatogenic elements could also be involved was seen in the accumulation of high frequencies of malformed spermatozoa by Week 6 . A bimodal distribution was also obtained due to the evident drop in abnormal sperm frequency at Week 5 . The data thus indicated the possible consecutive participation of two distinct populations of spermatogenic cells which was temporally well delineated. The delineation was only marginal in the testis $(P=0 \cdot 10)$ but significant in both the caput $(P<0.05)$ and the cauda $(P<0.01)$.

Because of the possible involvement of two populations of cells in the generation of abnormal spermatozoa, it seemed desirable to enquire whether their response to radiation damage was also distinct in terms of the types of shape abnormalities they each could produce. The perturbations in shape that a single dose of $6 \mathrm{~Gy}$ produced are shown in Fig. 7. The changes in the testis were characterized by a long-term decline in the frequency of perforatorium defects. Concurrently, there was a marked increase in the incidence of collapsed spermatozoa. Variations of smaller amplitude could also be seen in the other types of abnormalities, particularly in the case of the 'unidentifiable' and 'doubles' categories which displayed transient increases. The clear similarity between the testicular profiles of abnormal spermatozoa at 2 and 5 weeks after irradiation indicated that responses to X-rays could not be attributed to specific cell populations. Return to an approximately 
normal distribution of sperm shape abnormalities occurred by Week 9 . Taken together, the data on the incidence of abnormal spermatozoa and the distribution of abnormalities indicated that the induction of shape alteration could overlap several spermatogenic cell populations, but that their response to damage was uniform. None of the temporal changes in the frequencies detected in the testis was reflected in the epididymal samples. In the epididymis, the distributional pattern of abnormality types was similar to that of control samples (not shown). The apparent lack of dispersion from the testis where cell shape is determined suggested that sperm movement was either reduced or absent, thus resulting in the accumulation of locally induced damage. To test for this eventuality, an investigation of labelled spermatozoa was undertaken.

\section{Kinetics of sperm movement}

Contrary to expectations, the detailed analysis of labelled sperm movement revealed that the rate of transport was not affected by irradiation (Fig. 8). In control and experimental mice, labelled spermatozoa first appeared in the testis about 20 days after thymidine injection. According to peak labelling, the total transit time from the testis to the cauda was 5 days. The superimposability of the kinetic curves derived from the testis and the regions of the epididymis demonstrated that the progress of spermatozoa was unimpaired by X-rays. Within that time span, it took $24 \mathrm{~h}$ for spermatozoa to migrate from the testis to the caput epididymidis. Fluctuations of the label in the cauda epididymidis probably reflected considerable mixing with resident masses of gametes.

\section{Discussion}

The accumulation of radiation-induced malformed spermatozoa occurs in two phases, each apparently comprised of unique cellular elements. The first arises as a consequence of the rapid sloughing of non-dividing spermatids from the germinal epithelium. Those cells that remain associated with Sertoli cells most probably mature abnormally and, therefore, contribute to the malformed gametes which develop after exposure. The second phase of misshapen spermatozoa is provided by injured early spermatocytes whose contribution to the increased frequency of abnormally shaped spermatozoa is made $4-5$ weeks after exposure. Based on morphological criteria alone, there are no indications that the damage in each of these populations is unique. Hence, the morphological response of spermatogenic cells to radiation damage seems to be generalized.

The contribution that spermatogonia make to the phenomenon of sperm loss (Edwards \& Sirlin, 1958; Oakberg, 1959; Clow \& Gilette, 1970) seems questionable since the azoospermic condition is already established 3 weeks after irradiation instead of the 35 days that it would require (Meistrich et al., 1978). Based on the data presented, the role of surviving spermatogonia may be limited to the recovery phase of the regenerating epithelium.

There does not seem to be strong support either for the hypothesis that damage to spermatocytes is primarily involved in sperm losses. Injury to spermatocytes usually takes the form of a detectable delay in sperm production. The data on labelled spermatozoa clearly show that spermatocytes are impervious to radiation even at 600 rads since they produce spermatozoa at the same rate as control animals. A similar absence of a delay was reported by Bateman $(1956,1958)$. While discrete stages of meiosis are known to be susceptible to radiation damage (Oakberg \& DiMinno, 1960 ), the dose used here is well within the tolerance of the more resistant meiotic stages of spermatocytes.

Spermatophagy by Sertoli cells (Fawcett \& Burgos, 1956; Bawa, 1963) or by testicular macrophages (Holstein, 1978) has also been invoked to account for sperm losses. Its proper role is difficult to assess since little reference is normally made to it even in well documented cases of reduced sperm counts. It is suggested that testicular spermatophagy is unlikely to induce the $98 \%$ sperm loss observed here. In addition, no spermatophagy was ever observed in conjunction with the non-spermatogenic cells present in the epididymis of irradiated animals. The combined 
evidence overwhelmingly favours the hypothesis that epithelial sloughing is responsible for sperm loss in irradiated animals.

The absence of a demonstrable azoospermic condition within the cauda epididymidis is contrary to previous reports on the effects of radiation (Bruce et al., 1974; Hahn et al., 1976; Wyrobek et al., 1980). This may be the result of inappropriate definitions since an oligospermic condition must exceed the $50 \%$ fluctuation in sperm number that normally characterizes the cauda. For this reason, the monitoring of testicular sperm number may be a better indicator of sperm dynamics as others have already discovered (Meistrich et al., 1984).

The appearance of non-sperm elements in damaged epididymides has been reported before (Abe et al., 1982; Auroux, 1984) but has not previously been linked to radiation injury. The apparent homogeneity of the sloughed population indicates that the epithelium is specifically affected by the irradiation. A possible cause for this selectivity is the stringent relationship that seems to exist between Sertoli cells and round spermatids (Zipparo et al., 1980; Boitani et al., 1983; Welsh et al., 1985; Van Der Donk et al., 1986). Severe disturbances such as ionizing radiation may, therefore, upset the delicate balance between the two populations of cells and disrupt their association.

However extensive the sloughing of round spermatids may be, the data are inconsistent with the more gradual decline in sperm numbers observed in this study (Fig. 7). Perhaps a significant proportion of immature spermatids may remain unaffected and eventually mature into spermatozoa. Alternatively, the selective detachment of round spermatids may leave more mature spermatids potentially capable of completing their ultimate maturation. The development of azoospermia could therefore be due to the combination of cellular loss followed by the maturation depletion of resistant elements.

The timing of the emergence of increased malformed spermatozoa indicates that maturational dysfunction during spermiogenesis may also occur in addition to mutational events in spermatocytes (Bruce et al., 1974). The probability that structural elements in mature spermatids and spermatozoa can be affected by ionizing radiation is inferred from other studies in which alterations in membrane proteins were reported (Todo et al., 1982; Schuurhuis et al., 1984). Considerations of mature sperm DNA being also affected by gamma irradiation cannot be excluded and are presently being investigated. These should significantly enhance the study of the chromosomal nature of radiation damage conducted in other laboratories (Generoso et al., 1984).

The disparate distribution of abnormality types throughout the reproductive system of mice is presently unclear. The unimpeded movement of spermatozoa from the testis to the caput is accompanied by the selective removal of certain morphologically aberrant types of gametes. That the spermatophagic activity of Sertoli cells is enhanced when challenged with damaged cells (Holstein, 1978) or during reproductive pathologies leading to subfertile conditions (Schulze et al., 1976) has already been shown. But the mechanism behind its apparent selectivity remains to be elucidated.

The resiliency of the reproductive system to radiation damage substantiates a similar report by Edwards \& Sirlin (1958) in which sperm movement was unaffected by a 500 rad dose. This, however, has the practical effect of populating the cauda epididymidis with a large complement of abnormally shaped gametes whose genetic and developmental potential could be severely compromised. Continued efforts to resolve the biochemical nature of radiation damage on gametes are, therefore, entirely warranted. The determination of damage to key biochemical constituents such as DNA and membrane proteins may be particularly useful.

I thank Dr R. Balhorn for continued support throughout the work, for valuable suggestions, and for helpful criticism of the manuscript; the Flagstaff Medical Center for the use of the therapeutic Cobalt equipment; Dr E. Clark and Ms K. Mihlfeld for help with the radiology; Ms P. Waters for histological preparations; and Ms S. Mason for technical help.

This research was supported in part by a Minority Biomedical Research Support (NIH) Grant No. SO6-RR08215-02. 


\section{References}

Abe, K., Takano, H. \& Ito, T. (1982) Appearance of peculiar epithelial cells in the epididymal duct of the mouse ligated epididymis. Biol. Reprod. 26, 501-509.

Auroux, M. (1984) Nonspermatozoal cells in human sperm: a study of 1243 subfertile and 253 fertile men. Archs Androl. 12, 197-201.

Balhorn, R., Gledhill, B.L. \& Wyrobek, A.J. (1977) Mouse sperm chromatin proteins: quantitative isolation and partial characterization. Biochemistry, N.Y. 16, 4074-4080.

Balhorn, R., Weston, S., Thomas, C. \& Wyrobek, A.J. (1984) DNA packaging in mouse spermatids: synthesis of protamines variants and four transition proteins. Expl Cell Res. 150, 298-308.

Bateman, A.J. (1956) Sensitivity of immature mouse sperm to the mutagenic effects of X-rays. Nature, Lond. 178, 1278-1280.

Bateman, A.J. (1958) Mutagenic sensitivity of maturing germ cells in the male mouse. Heredity 12, 213-232.

Bawa, S.R. (1963) Fine structure of the Sertoli cell of the human testis. J. Ultrastruct. Res. 9, 459-474.

Bloom, W. \& Fawcett, D.W. (1962) A Textbook of Histology. W.B. Saunders Co., Philadelphia.

Boitani, C., Palombi, F. \& Stefanini M. (1983) Influence of Sertoli cell product upon the in vitro survival of isolated spermatocytes and spermatids. Cell Biol. Intern. Reports 7, 383-393.

Bruce, W.R., Furrer, R. \& Wyrobek, A.J. (1974) Abnormalities in the shape of murine sperm after the acute testicular X-irradiation. Mut. Res. 23, 381-386.

Clermont, Y. (1963) The cycle of the seminiferous epithelium in man. Am. J. Anat. 112, 35 45.

Clow, D.J. \& Gilette, E.L. (1970) Survival of type A spermatogonia following X-irradiation. Rad. Res. 42, $397-404$.

Edwards, R.G. \& Sirlin, J.L. (1958) The effect of 200 R of $\mathrm{X}$-rays on the rate of spermatogenesis and spermiogenesis in the mouse. Expl Cell Res. 15, 522-528.

Fawcett, D.W. \& Burgos, M.H. (1956) The fine structure of Sertoli cells in the human testis. Anat. Rec. 124, 401-402.

Generoso, W.M., Cain, K.T., Cachiero, N.L.A. \& Cornett, V.C. (1984) Response of mouse spermatogonial stem cells to X-ray induction of heritable reciprocal translocations. Mut. Res. 126, 177-187.

Hahn, E.W., Feingold, S.M. \& Nisce, L. (1976) Aspermia and recovery of spermatogenesis in cancer patients following incidental gonadal irradiation during treatment: a progress report. Radiology 119, 223-225.

Holstein, A.F. (1978) Spermatophagy in the seminiferous tubules and excurrent ducts of the testis in the Rhesus monkey and in man. Andrologia 10, 331-352.

Meistrich, M.L., Hunter, N.R., Suzuki, N., Trostle, P.K. \& Withers, R.H. (1978) Gradual regeneration of mouse testicular stem cells after exposure to ionizing radiation. Rad. Res. 74, 349-362.

Meistrich, M.L., Finch, M., Lu, C.C., de Ruiter-Bootsma, A.L. \& de Rooij, D.G. (1984) Strain differences in the response of mouse testicular stem cells to fractionated radiation. Rad. Res. 97, 478-487.
Oakberg, E.F. (1959) Initial depletion and subsequent recovery of spermatogonia of the mouse after $20 \mathrm{R}$ of gamma rays and 100,300 , and $600 \mathrm{R}$ of $\mathrm{X}$-rays. $\mathrm{Rad}$. Res. 11, $700-719$.

Oakberg, E.F. (1975) Effects of radiation on the testis. In Handbook of Physiology, Section $f$ : Endocrinology, vol. 5, pp. 233-243. Eds R. O. Greep \& E. B. Astwood. Am. Physiol. Soc., Washington, D.C.

Oakberg, E.F. \& DiMinno, R.L. (1960) X-ray sensitivity of primary spermatocytes of the mouse. Int. J. Rad. Biol. 2, 196-209.

Pinkel, D., Gledhill, B.L., van Dilla, M.A., Lake, S. \& Wyrobek, A.J. (1983) Radiation-induced DNA content variability in mouse sperm. Rad. Res. 95, $550-565$.

Pogany, G.C. \& Lewis, K.C. (1985) Enhancement of cathepsin B activity in irradiated mouse testis. $J$. Radiat. Res. 26, 248-256.

Pogany, G.C., Corzett, M., Weston, S. \& Balhorn, R. (1981) DNA and protein content of mouse sperm: implications regarding sperm chromatin structure. Expl Cell Res. 136, 127-136.

Schulze, C., Holstein, A.F., Schirren, C. \& Korner, F. (1976) On the morphology of the human Sertoli cells under normal conditions and in patients with impaired fertility. Andrologia 8, 167-178.

Schuurhuis, G.L., Hammes, J., Vos, J., Molenaar, I. \& Konings, A.W.T. (1984) Radiation-induced structural changes in membrane proteins of human erythrocytes and ghosts and the relation to cellular morphology. Int. J. Radiat. Biol. 45, 159-177.

Todo, T., Yonei, S. \& Kato, M. (1982) Radiation-induced structural changes in human erythrocyte membrane proteins revealed by sodium dodecyl sulfate/ polyacrylamide gel electrophoresis. Rad. Res. 89, 408-419.

Van Der Donk, J.A., De Ruiter-Bootsma, A.L., UlteeVan Gessel, A.M. \& Wauben-Penris, P.J.J. (1986) Cell-cell interaction between rat Sertoli cells and mouse germ cells in vitro. Expl Cell Res. 164, $191-198$.

Welsh, M.J., Ireland, M.E. \& Treisman, G.J. (1985) Stimulation of rat Sertoli cell adenylate cyclase by germ cells in vitro. Biol. Reprod. 33, 1050-1056.

Wyrobek, A.J. \& Bruce, W.R. (1975) Chemical induction of sperm abnormalities in mice. Proc. natn. Acad. Sci., U.S.A. 72, 4425-4429.

Wyrobek, A.J., Heddle, J.A. \& Bruce, W.R. (1975) Chromosomal abnormalities and the morphology of mouse sperm heads. Can. J. Genet. Cytol. 17, 675-681.

Wyrobek, A.J., da Cunha, M., Gordon, L., Watchmaker, G., Gledhill, B.L., Gamble, J. \& Meistrich, M.L. (1980) Sperm abnormalities in cancer patients. Proc. Am. Assoc. Cancer Res. \& Am. Soc. Clin. Oncol., 71st Ann. Meeting. 21, 196, Abstr.

Zipparo, E., Geremia, R., Russo, M. \& Stefanini, M. (1980) Surface interaction in vitro between Sertoli cells and germ cells at different stages of spermatogenesis. Am. J. Anat. 159, 385-388. 